\title{
Avaliação de clones de seringueira quanto à resistência ao oídio
}

\author{
Karina Goulart Tumura ${ }^{1,2}$, Marília Pizetta ${ }^{1}$, Lucas Luís da Silva ${ }^{1}$, Edson Luiz Furtado ${ }^{1,2}$
}

\begin{abstract}
${ }^{1}$ Departamento de Defesa Fitossanitária, Faculdade de Ciências Agronômicas, Universidade Estadual Paulista, CP 237, 18603-970, Botucatu-SP; ${ }^{2}$ Bolsista CNPq

Autor para correspondência: Edson Luiz Furtado (elfurtado@ fca.unesp.br)

Data de chegada: 25/10/2013. Aceito para publicação em: 10/07/2013.
\end{abstract}

\section{RESUMO}

Tumura, K.G.; Pizetta, M.; Silva, L.L.; Furtado, E.L. Avaliação de clones de seringueira quanto à resistência ao oídio. Summa Phytopathologica, v.39, n.4, p.252-257, 2013.

Foi realizada a avaliação de cinco clones comerciais de seringueira em jardim clonal quanto à resistência ao oídio, bem como a flutuação da doença correlacionando-a com as condições climáticas reinantes no período de estudo. Para tal avaliação, foi desenvolvida uma escala diagramática, elaborada a partir de 150 folíolos centrais coletados em diversas idades e níveis de ataque aleatoriamente. A validação da escala foi realizada por cinco avaliadores. Pelos resultados obtidos, todos os clones mostraram suscetibilidade ao patógeno, sendo verificado maior ataque aos folíolos mais jovens. De acordo com os dados climáticos, as temperaturas amenas e umidade relativa abaixo de $60 \%$ favoreceram a epidemia.

Palavras-chave adicionais: Hevea, Oidium heveae, escala diagramática, epidemiologia

\section{ABSTRACT}

Tumura, K.G.; Pizetta, M.; Silva, L.L.; Furtado, E.L. Evaluation of rubber tree clones for resistance to powdery mildew. Summa Phytopathologica, v.39, n.4, p.252-257, 2013.

Five commercial rubber tree clones in a clonal nursery were assessed for resistance to powdery mildew, as well as for the disease fluctuation and its correlation with the climate conditions in the study period. For this assessment, a diagrammatic scale was developed from 150 central leaflets randomly collected at different ages and attack levels. Validation of scale was done by five assessors. Results indicated that all clones showed susceptibility to the pathogen, and the attack was higher for younger leaflets. According to the climate data, mild temperatures and relative humidity below $60 \%$ favored the epidemic.

Additional keywords: Hevea, Oidium heveae, diagrammatic scale, epidemiology

Oídios atacam inúmeras espécies vegetais, e dentre as espécies florestais cultivadas no Brasil e atacadas, destacam-se a seringueira e o eucalipto. Considerada como uma das mais importantes doenças da seringueira, o oídio ocorre com maior intensidade nos países asiáticos. Sua ocorrência no Brasil fora relatada em 1958, no Estado de São Paulo, e depois tida como erradicada, porém voltou a ocorrer em vários municípios do Estado e também no litoral do Espírito Santo, atacando plantas em diversas fases de desenvolvimento (10).

Apresentam uma forma evoluída de parasitismo, pois raramente levam seu hospedeiro à morte. Os sintomas são facilmente identificáveis e sempre se manifestam na forma de eflorescência ou bolor pulverulento, de coloração branca ou levemente cinza. Esta eflorescência, formada por micélio, conidióforos e conídios do patógeno, pode ser encontrada em diversos órgãos vegetais como meristemas, ramos jovens, flores, frutos em formação e, principalmente, na face superior das folhas. Em alguns casos, no entanto, pode ser constatada também na face inferior. O patógeno coloniza a área foliar junto às nervuras, especialmente próximo à nervura principal (5). O oídio dissemina-se através do vento, respingo de chuvas e no contato entre plantas infectadas (9).
Patógenos causadores de oídio são parasitas biotróficos obrigatórios de plantas, que para a obtenção de nutrientes formam haustórios no interior das células do hospedeiro, sem, no entanto matá-las. Somente uma fina rede micelial cresce sobre a superfície foliar em forma de colônias. Cada colônia forma numerosos haustórios que retiram nutrientes das células epidérmicas e mesofílicas, garantindo a produção de conidióforos e conídios (22).

Com relação à germinação, o ciclo assexual começa quando um conídio é depositado sobre uma superfície apropriada da planta. A germinação conidial é favorecida por condições de alta umidade relativa, porém, a água livre causa a perda da viabilidade dos conídios. Durante a germinação, o conídio forma um tubo germinativo primário curto dentro de uma ou duas horas (22). O tubo germinativo não penetra a célula epidérmica e tem função de ancorar o conídio na superfície foliar (6). O "peg" de penetração, que é formado na face inferior do apressório, é a estrutura pela qual o patógeno consegue penetrar na célula epidérmica do hospedeiro. Na célula penetrada, forma-se um agregado citoplasmático contendo calose, polifenóis, lipídios e proteínas, incluindo enzimas hidrolíticas, mas não suberina, lignina ou pectina $(7,14,15,24)$. 
Finalmente, as folhas atacadas amarelecem e caem, causando grande desfolha (17).

O estudo do patógeno, sua flutuação anual e sua correlação com as condições climáticas estão diretamente ligados ao manejo que será aplicado e, também aos métodos de controle da doença, tendo em vista sua importância econômica para a produção de látex (devido ao ataque às folhas) e sementes, já que o fungo pode atacar também as flores. Para realizar o estudo de sua flutuação, com uma análise detalhada, definem-se os critérios para escolher o melhor método de avaliação. No caso de doenças foliares, como o oídio, a severidade é o parâmetro mais utilizado e para determinála as escalas diagramáticas são fundamentais (11).

Como a disseminação desse fungo e sua severidade são altamente influenciadas pela radiação, temperatura, precipitação, evapotranspiração, condensação de água, umidade relativa e pelo vento (1), este trabalho tem por objetivos: a) desenvolver uma escala diagramática para a avaliação da doença nas diferentes cultivares; b) estudar a flutuação da doença correlacionando-a com o clima, determinando-se em qual época e em quais condições climáticas ocorre maior desenvolvimento da doença; e c) verificar a resistência de cultivares comerciais a doença em condições de jardim clonal.

\section{MATERIAL E MÉTODOS}

O estudo foi conduzido em uma área experimental com cultura de seringueira já instalada, pertencente ao Departamento de Proteção Vegetal da Faculdade de Ciências Agronômicas, UNESP, Câmpus de Botucatu, SP (latitude: $22^{\circ} 51^{\prime}$ S; longitude: $48^{\circ} 26^{\prime} \mathrm{W}$; e altitude: $786 \mathrm{~m}$ ). O período foi de 11 meses (julho de 2006 a maio de 2007) para verificação da flutuação da doença de acordo com as condições climáticas.

O clima local, segundo a classificação de Köppen é temperado quente e úmido (Cfa), moderado chuvoso, com temperatura média do mês mais quente igual a $23,1^{\circ} \mathrm{C}$ (fevereiro), e de $17,1^{\circ} \mathrm{C}$ (julho) no mês mais frio, com média anual de $20,3^{\circ} \mathrm{C}$. A precipitação pluviométrica média anual é de $1428,4 \mathrm{~mm}$, mais concentrada no verão, com 246,2mm (janeiro) e 36,1 mm (agosto) para os meses de maior e menor precipitação, respectivamente (Cunha e Martins, 2009).

Utilizaram-se cinco cultivares: RRIM 600, PR 255, RRIM 701, GT 1 e PB 235 com quatro repetições cada um, onde foram avaliadas em condição de epidemia aberta. Todas as plantas se encontravam com uniformidade de brotações, devendo ser ressaltado que em condições de jardim clonal pode haver brotações novas o ano todo.

\section{A. Elaboração e validação da escala diagramática}

Coletaram-se 150 folíolos centrais aleatoriamente, os quais apresentavam diversas idades e níveis de ataque.

Os folíolos foram digitalizados obtendo-se: a área total e a área lesionada, e assim determinou-se a severidade da doença real em porcentagem. A partir dos valores obtidos estabeleceu-se a escala, sendo seus níveis intermediários definidos de acordo com a lei de Weber-Fechner de acuidade visual, ou seja, em escala logarítmica de infecção.

A validação da escala foi realizada por cinco avaliadores, todos sem experiência na quantificação de doenças. Primeiramente, realizouse uma avaliação sem a utilização da escala e depois com a utilização da mesma.

Através de análise de regressão simples, determinou-se a acurácia e a precisão da escala, tendo como variável independente a severidade estimada eletronicamente e como variável dependente, a severidade estimada pelos avaliadores. Na comparação da acurácia dos dados estimados com os reais utilizaram-se os parâmetros intersecção (a) e inclinação da reta (b) e na precisão o coeficiente de determinação $\left(\mathrm{R}^{2}\right)$.

Considerou-se com maior acurácia o avaliador onde as estimativas resultaram em equações de regressão onde "a" e "b" não diferiram estatisticamente de 0 e 1 respectivamente e com maior precisão o avaliador com estimativa que permitiu o ajuste do modelo linear com os maiores do coeficiente de determinação $\left(\mathrm{R}^{2}\right)$.

As análises de regressão foram obtidas a partir do programa Microsoft Excel 2000® ${ }^{\circledR}$ (Microsoft Corporation, 2000).

\section{B. Avaliações de campo}

Após a confecção e validação da escala diagramática, iniciaram-se as avaliações no jardim clonal. Foi utilizado o delineamento de blocos casualizados com cinco tratamentos e dez repetições cada onde, quinzenalmente, as plantas foram avaliadas através da porcentagem de área foliar lesionada utilizando-se a escala. Para tal avaliação, foram marcados dois lançamentos aleatoriamente em cada planta, onde contabilizou-se o número de folhas, o número de folíolos, o número de folíolos infectados, o estágio de desenvolvimento do lançamento bem como a porcentagem de área lesionada pelo fungo de acordo com a escala diagramática desenvolvida.

A partir dos dados da doença em cada avaliação, foi calculada, para cada clone a área abaixo da curva de progresso da doença (AUDPC - Area Under Disease Progress Curve), de acordo com a equação abaixo, proposta por Campbell \& Madden (5):

$$
A U D P C=\sum_{i}^{n-1}\left(\frac{y_{i}+y_{i+1}}{2}\right)\left(t_{i+1}-t_{i}\right)
$$

em que:

$\mathrm{n}=$ número de avaliações;

$\mathrm{y}=$ intensidade da doença;

$\mathrm{t}=$ tempo quando da avaliação da intensidade da doença;

$\left(\mathrm{y}_{\mathrm{i}}+\mathrm{y}_{\mathrm{i}+1}\right)=$ altura média do retângulo entre os pontos $\mathrm{y}_{\mathrm{i}}$ e $\mathrm{y}_{\mathrm{i}+1} \mathrm{e}$;

$\left(t_{i+1}-t_{i}\right)=$ diferença da base do retângulo entre os pontos $t_{i+1}$ e $t_{1}$

Os resultados obtidos no cálculo das AUDPC foram submetidos à análise de variância e as médias comparadas pelo teste de Tukey ao nível de 5\% de significância.

A análise estatística das avaliações de campo foi feita pelo teste de Tukey através do programa Estat. Para fins de análise estatística os valores originais foram transformados em $(x+0,5)^{1 / 2}$.

Os dados climáticos foram obtidos na estação meteorológica da Faculdade de Ciências Agronômicas - UNESP/Botucatu.

\section{RESULTADOS E DISCUSSÃO}

\section{A. Escala diagramática}

A severidade máxima encontrada nos 150 folíolos coletados foi de $50 \%$ e o valor mínimo de $0 \%$. Os níveis intermediários para a escala, seguindo-se a lei de Weber-Fechner, foram ajustados em: $0 \% ; 2,5 \%$; $5,0 \% ; 10,0 \% ; 20,00 \% ; 38,0 \%$ e $50,0 \%$ (Figura 1 ).

Na validação da escala todos os avaliadores apresentaram maior precisão em suas avaliações quando utilizaram a escala diagramática (Tabela 1). 


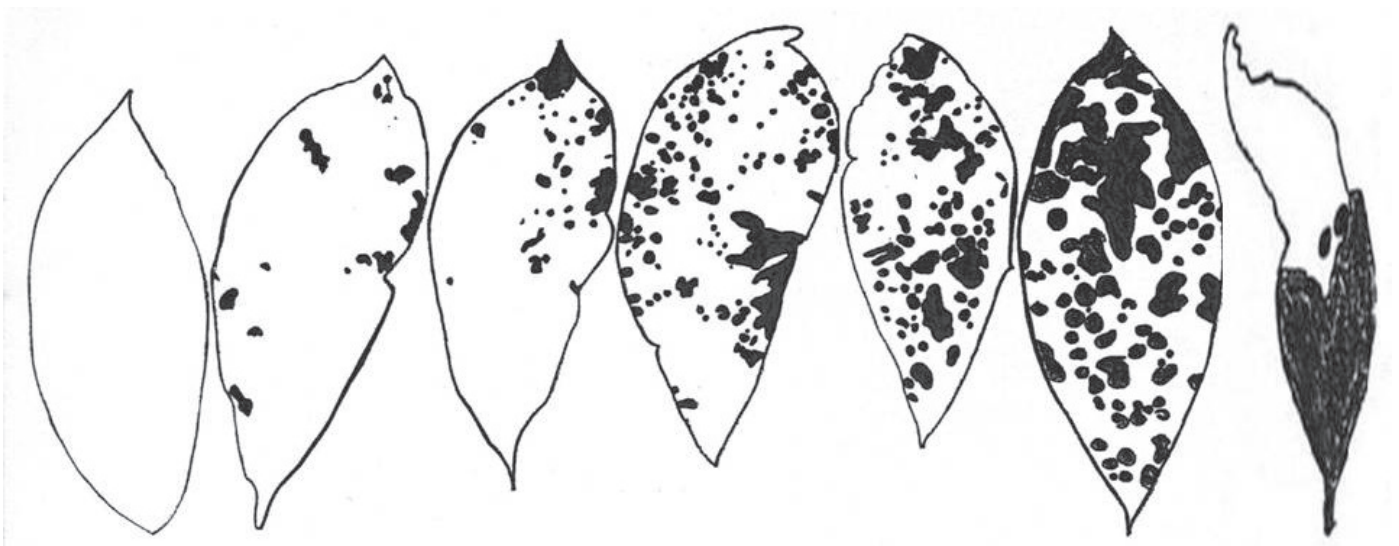

Figura 1. Escala diagramática de severidade do oídio (Oidium heveae Steinn.) em seringueira (Hevea spp.), onde a coloração escura representa a área recoberta pelo patógeno

De maneira geral, os avaliadores apresentaram maior precisão que acuracidade, havendo a tendência de superestimar os danos na avaliação sem escala e subestimar utilizando-a.

Para as avaliações visuais do oídio, feitas utilizando-se a escala diagramática, se obteve valores de precisão inferiores a 95\%, o que é considerado aceitável por Kranz (13).

A presença de erros sistemáticos na mensuração da severidade, mesmo para os avaliadores com maiores precisões, indica a diferença entre estimativas acuradas e precisas, como constatado por Nutter Junior et al. (19) na mensuração da mancha foliar de Agrostis palustris Huds. As avaliações com baixa acurácia não são um problema sério uma vez que os desvios têm o mesmo padrão (18).

\section{B. Avaliações de campo}

Visando determinar a resistência dos clones ao patógeno em curvas de flutuação da doença, foram feitas avaliações quinzenais das plantas.

Todos os clones mostraram suscetibilidade ao patógeno apresentando os danos citados anteriormente $(2,3)$. Foi verificado maior ataque aos lançamentos mais jovens.

No Brasil, em ataque relatado por Stradioto \& Zambolin (23), no município de Buritama-SP, as cultivares RRIM 527 e PR 261 foram as mais atacadas; as cultivares BSA 20, RRIM 623, GT 711, BD 5, FX 3703, BD 10, MDF 180 e RRIM 600 apresentaram pouco ataque, e as cultivares IAN 3087, C 290, FX 4098, RRIM 526, IAN 6159, FX 3844, GT 1 e FX 2261 não apresentaram os sintomas da doença, o que
Tabela 1. Acurácia e precisão representadas pela intersecção (a), inclinação (b) e coeficiente de determinação nas avaliações da severidade do oídio pelos avaliadores, sem e com uso da escala diagramática.

\begin{tabular}{ccccccc}
\hline & \multicolumn{3}{c}{ Sem escala } & \multicolumn{3}{c}{ Com escala } \\
\cline { 2 - 7 } Avaliador & $\mathbf{a}$ & $\mathbf{b}$ & $\mathbf{R}^{\mathbf{2}} \boldsymbol{( \% )}$ & $\mathbf{a}$ & $\mathbf{b}$ & $\mathbf{R}^{\mathbf{2}}(\boldsymbol{\%})$ \\
\hline 1 & 0,72 & 0,24 & 65 & 1,19 & 0,25 & 80 \\
2 & 0,99 & 0,15 & 76 & 0,82 & 0,11 & 80 \\
3 & 0,90 & 0,48 & 61 & 0,84 & 0,20 & 70 \\
4 & 0,86 & 0,84 & 59 & 0,99 & 0,86 & 60 \\
5 & 1,37 & 0,55 & 29 & 1,07 & 0,92 & 57 \\
\hline Média & 0,88 & 0,49 & 55 & 0,91 & 0,47 & 67 \\
\hline
\end{tabular}

difere dos resultados encontrados em Botucatu-SP no presente estudo. O clone GT 1 apresentou juntamente com o clone PB 235, o maior nível de desfolha bem como área lesionada (Figura 2).

Em termos de porcentagem de área foliolar lesionada, o clone com menor índice de lesão foi o RRIM 600, como encontrado na literatura (23). Os clones com maiores áreas lesionadas foram os clones PB 235, PR 255 e GT 1 (Figura 3).

A resistência clonal ao oídio, inferida através da ASCPD (Tabela 2), é maior no clone RRIM 600, seguido do RRIM 701. Os clones mais suscetíveis são o PB 235, GT1 e PR 255.

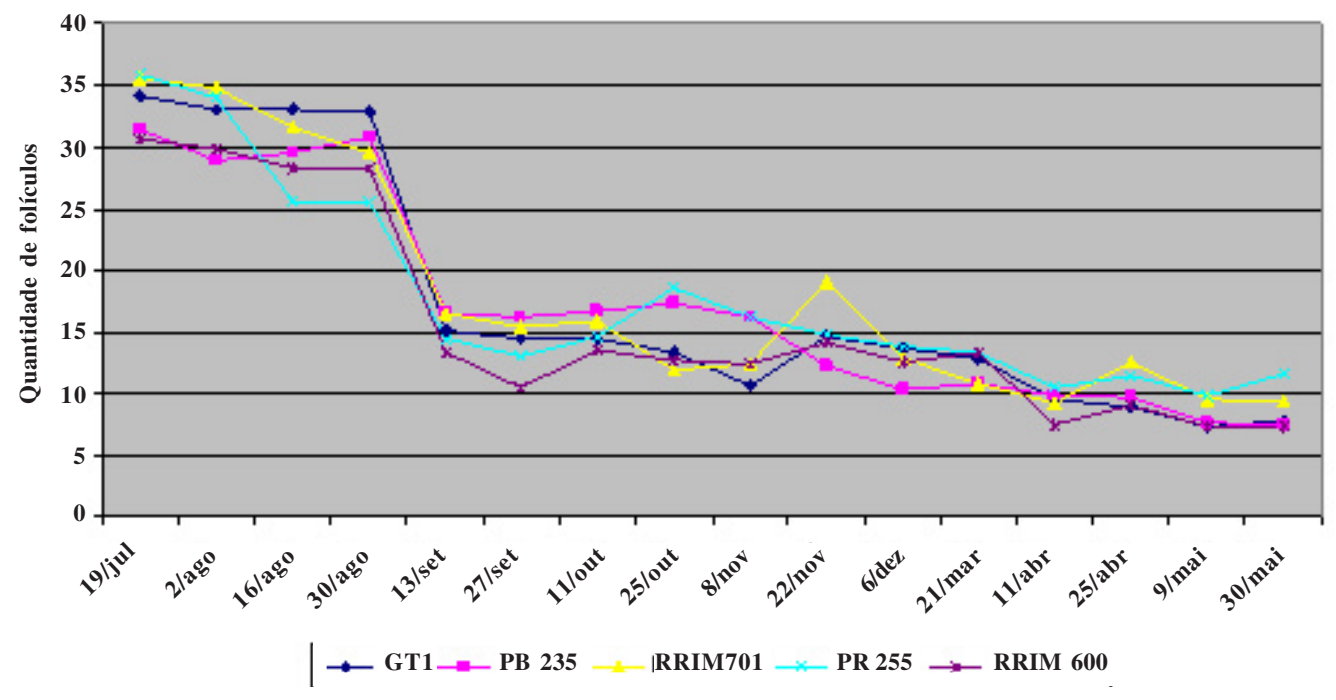

Figura 2.

Quantidade média de folíolos por clone em cada período do ano. 


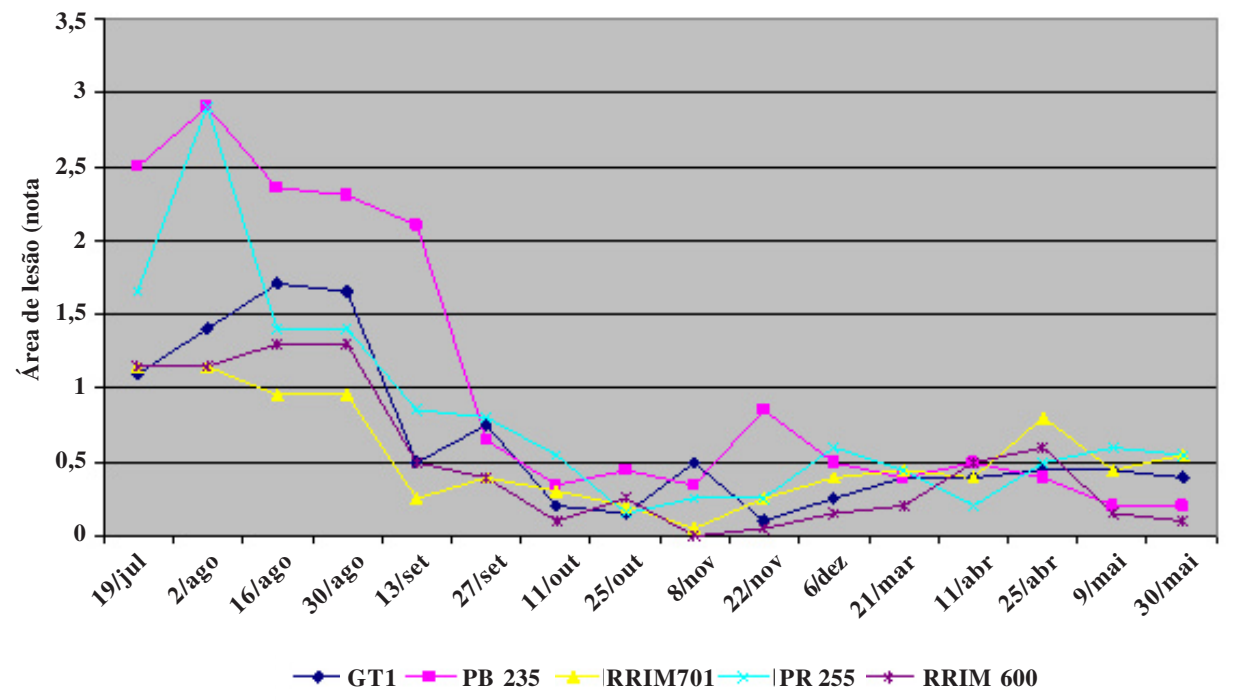

Figura 3. Área lesionada média (aferida por nota) por clone em cada avaliação (notas: 0 - $0,0 \%$; $1-2,5 \% ; 2-5,0 \% ; 3-10,0 \% ; 4-$ $20,0 \% ; 5-38,0 \% ; 6-50,0 \%)$.

Tabela 2: Área sobre a curva do progresso de oídio em cinco clones de seringueira.

\begin{tabular}{lc}
\hline CLONE & ASCPO (Área sob a curva de progresso de oídio) \\
\hline GT 1 & $1155,7 \mathrm{AB}$ \\
PB 235 & $1498,7 \mathrm{~A}$ \\
RRIM 701 & $624,40 \mathrm{AB}$ \\
PR 255 & $1036,02 \mathrm{AB}$ \\
RRIM 600 & $419,30 \mathrm{~B}$ \\
\hline
\end{tabular}

CV $(\%)=25,03 \quad$ DMS $(\mathbf{5 \%})=14,25 \quad$ Dados transformados em $(x+0,5)^{1 / 2}$

Pouco se sabe a respeito dos fatores que influenciam a produção dos tipos de esporos que desempenham papel importante nos processos infectivos, sobrevivência e variabilidade do patógeno. Ruiz et al. (20) afirmam ser necessário o conhecimento de fatores meteorológicos que influenciam na incidência e severidade da doença para possibilitar a determinação de épocas do ano mais favoráveis ao patógeno.

Em suma, o conhecimento de fatores meteorológicos que influem na incidência e severidade da doença têm se mostrado uma ferramenta útil para a determinação das épocas do ano mais favoráveis à doença, visando à racionalização de medidas de controle (21).

A temperatura do ar pode ter um efeito importante em cada componente do patossistema e constitui a variável do ambiente mais comumente correlacionada com a incidência e a severidade das doenças de plantas (26). Deste modo a infecção, a colonização, a produção de inóculos, a dispersão e a sobrevivência constituem os elementos necessários para o desenvolvimento das epidemias em plantas (25), sendo que todos esses processos são afetados pelos fatores meteorológicos, principalmente temperatura e umidade do ar.

Os clones mais atacados pelo patógeno foram o GT 1, PB 235 e PR 255, sendo que a doença atingiu os níveis mais altos entre julho e agosto, decrescendo ao final de setembro (Figura 4). Pode-se observar que a queda no nível de infecção diminui com o aumento da temperatura, precipitação e umidade relativa, sendo menor nos meses mais quentes e úmidos. Faixas de temperatura entre $15^{\circ}$ e $25^{\circ} \mathrm{C}$ e umidade do ar em torno de $60 \%$, associada a períodos de baixa precipitação favoreceram a epidemia de oídio na área de realização do estudo (Figuras 5, 6 e 7), diferindo do encontrado na literatura, onde os dados de umidade relativa são de 75 a $80 \%$ (2).

Os oídios são favorecidos por baixa umidade relativa e quantidade de chuvas (16), como pode ser visto pelas Figuras 6 e 7. A temperatura favorável para germinação dos esporos e infecção da planta varia entre 20 e $25^{\circ} \mathrm{C}$ (12), sendo que temperaturas diurnas altas e noturnas amenas associadas a longos períodos de estiagem, observados no período de estudo (Figuras 5 e 7), favorecem a ocorrência de severas epidemias (4).

Não foi detectada a presença de resistência ao patógeno em nenhum dos clones testados, porém alguns apresentaram danos pouco

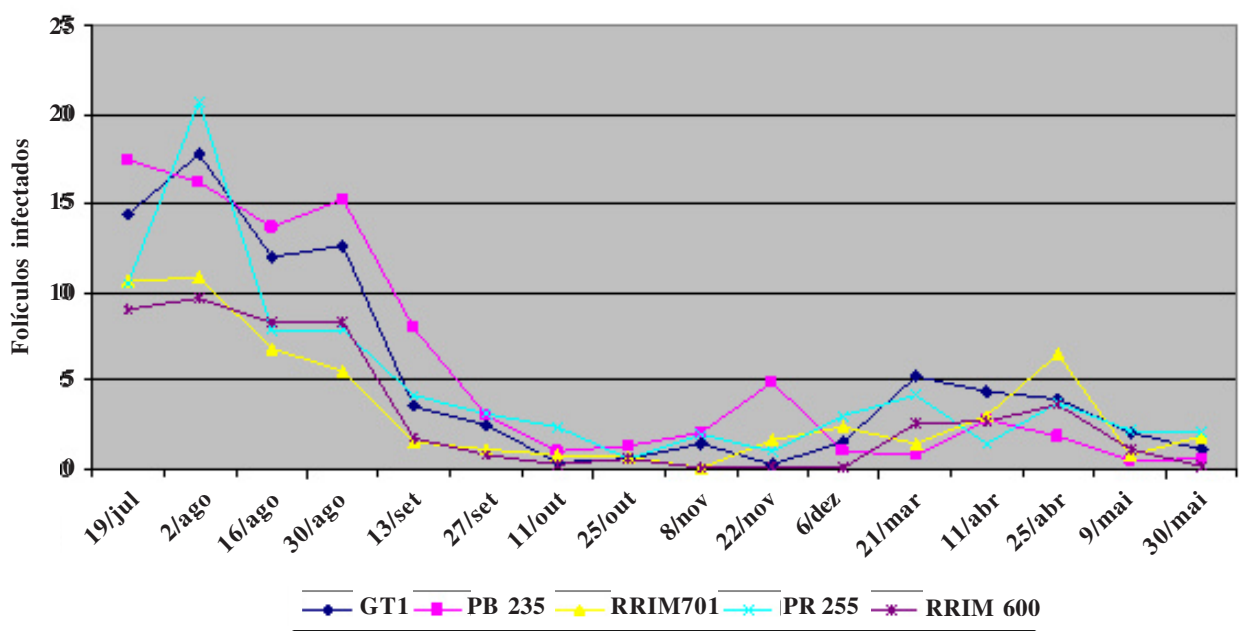

Figura 4.

Quantidade de folíolos infectados por clone 


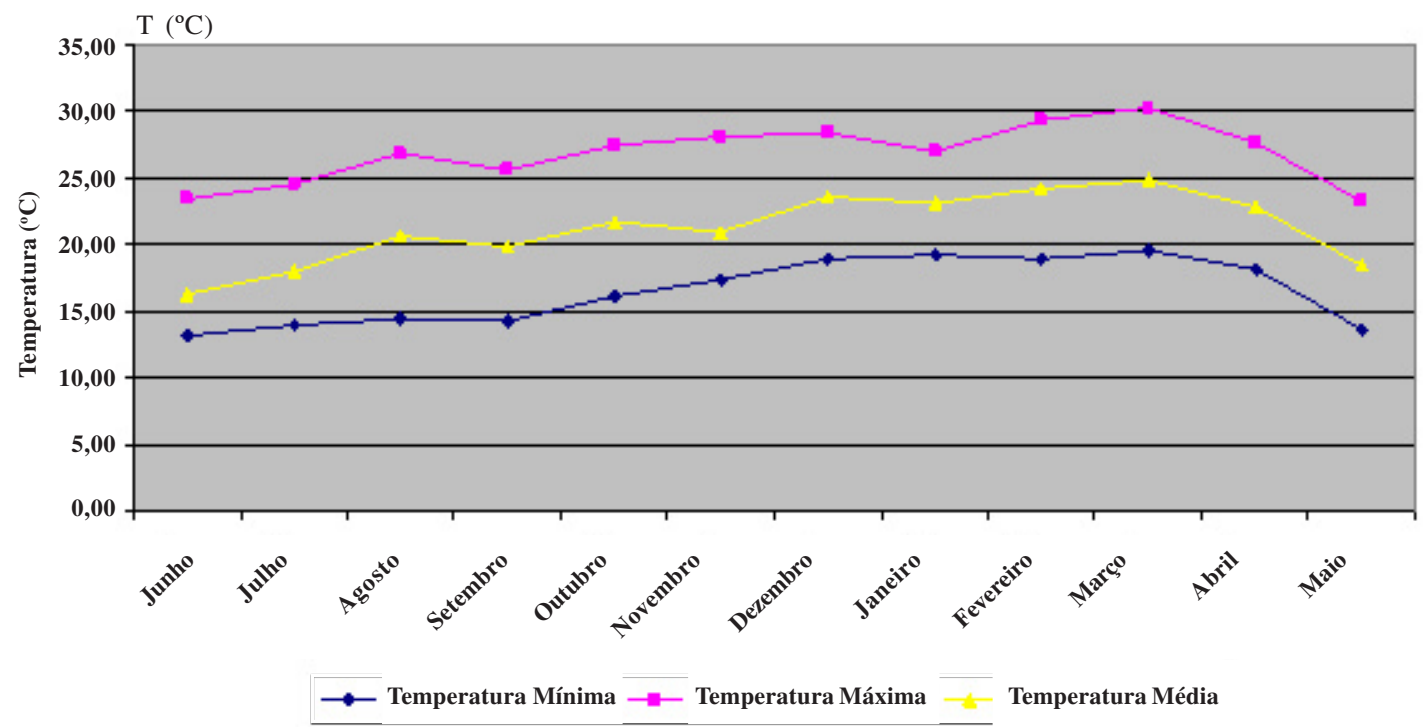

Figura 5. Temperatura média do ar $\left(\mathrm{T},{ }^{\circ} \mathrm{C}\right)$ no período de estudo

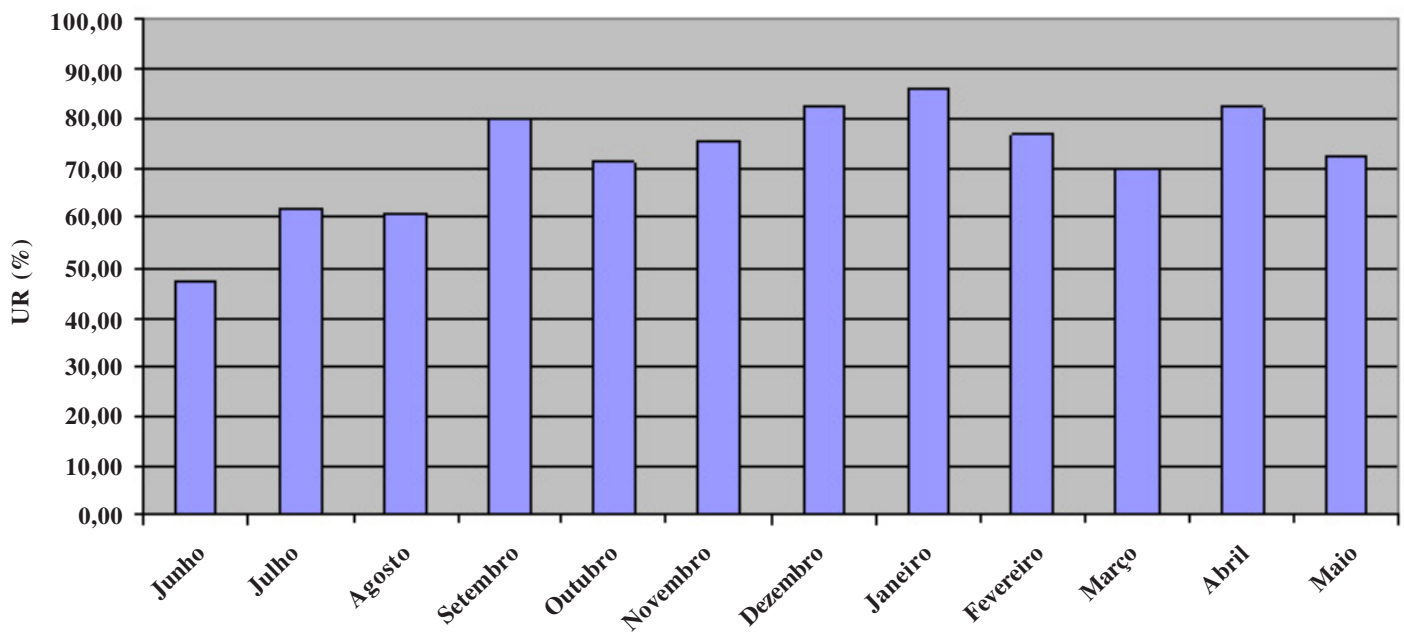

Figura 6. Umidade relativa média do ar (UR, \%) no período de estudo

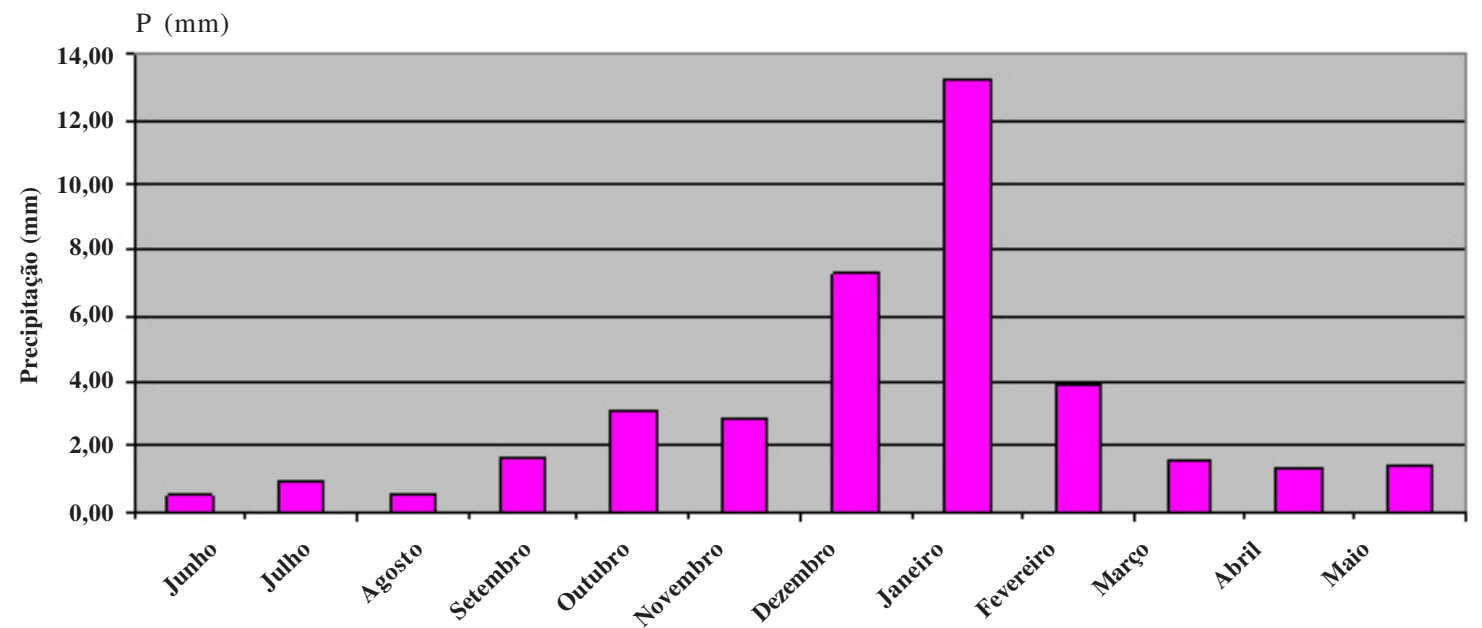

Figura 7. Precipitação pluviométrica em $\mathrm{mm} / \mathrm{dia}$, $(\mathrm{P}, \mathrm{mm})$ no período de estudo. 
significativos como o RRIM 600 com menor quantidade de folíolos infectados e também menor área lesionada. Os clones mais afetados pela doença foram o PB 235, PR 255 e GT 1. Todos obtiveram os maiores índices de queda de folíolos, maior quantidade de folíolos infectados e área lesionada.

À partir deste estudo pode-se concluir que: a) a escala diagramática desenvolvida possibilitou a quantificação adequada da doença; b) os clones mais suscetíveis a doença foram: PB 235, PR 255 e GT1 e; c) as temperaturas amenas e UR abaixo de 60\%, associadas à baixa pluviosidade, favoreceram a epidemia.

\section{AGRADECIMENTOS}

Os autores agradecem ao Conselho Nacional de Desenvolvimento Científico e Tecnológico por concessão de bolsa para que este trabalho fosse realizado.

\section{REFERÊNCIAS BIBLIOGRÁFICAS}

1. AUST, H.J. e HOYNINGEN-HUENE, J.V. Microclimate in relation to epidemics of powdery mildew. Annual Review of Phytopathology, Palo Alto: v.24, p.491-510, 1986.

2. BEDENDO, I. P Oídios. In: Amorim, L.; Bergamin Filho, A.; Kimati, H. (Ed.). Manual de fitopatologia. São Paulo: Ceres, 1995, v.1, p. 866-871.

3. BERGAMIN FILHO, A.; AMORIM, L. Doenças de plantas tropicais: epidemiologia e controle econômico. São Paulo: Agronômica Ceres, 1996. 289 p.

4. CAFÉ FILHO, A. C.; COELHO, M. V. S.; SOUZA, V. L. Oídios de hortaliças. In: STADNIK, M. J.; RIVERA, M. C. (Ed.). Oídios. Embrapa Meio Ambiente, Jaguariúna, 2001, p.285-302

5. CAMPBELL, C. L.; MADDEN, L. V. Introduction to plant disease epidemiology. New York: John Wiley, 1990.

6. CARVER, T. L. W. Pathogenesis and host-parasite interaction in cereal powdery mildew. In: HESS, W.; SINGH, R.; SINGH, U.; WEBER, D. Experimental and Conceptual Plant Pathology. New York, Gordon and Beach: 1988. v.2. p.351-381.

7. CARVER, T. L. W.; ZEYEN, R. J.; LYNGKJAER, M. F. Plant cell defenses to powdery mildew of graminae. Aspects of Applied Biology. Warwick, v.42, p.257-266, 1995.

8. CUNHA, A. R.; MARTINS, D. Classificação climática para os municípios de Botucatu e São Manuel, SP. Irriga. Botucatu: v. 14, p.1-11, 2009.

9. FURTADO, E. L.; SANTOS, C. A. G.; TAKAhASHI, S. S.; CAMARGO, F. R. A. Doenças em viveiro de Eucalyptus sp.: diagnóstico e manejo. Botucatu: (Votorantim Celulose e Papel, Unidade Florestal, Boletim Técnico, 1), 2001. 23p.

10.FURTADO, E.L.; SILVEIRA, A.P. Nova ocorrência de oídio da seringueira no Estado de São Paulo. São Paulo: Instituto Biológico, 1993. 3p. (Comunicado Técnico, 3).

11. GODOY, C.V.; CARNEIRO, S.M.T.P; IAMAUTI, M.T.; PRIA, M.D.; AMORIM, L.; BERGER, R.D. \& BERGAMIN FILHO, A. Diagrammatic scales for bean diseases: Development and validation. Journal of Plant Disease and Protection, Rostock: v.104, p.336-345, 1997.

12. GOLDBERG, N.P. Powdery mildew. In: PERNEZNY, K.; ROBERTS, P. D.; MURPhY, J. F.; GOLDBERG, N. P. (Ed.). Compendium of pepper diseases. APS Press: St. Paul, 2003, p.1920 .

13. KRANZ, J. Measuring plant disease. In: Kranz, J.; Rotem, J. (Ed.). Experimental techniques in plant disease epidemiology. Berlim: Springer Verlag, 1988. p. 35-50.

14. KUNOH, H.; HAYASHIMOTO, A.; HARUI, M.; ISHIZAKI, H. Induced suscetibility and enhaced resistance at the celular level in barley coleoptiles. I. The significance of timing of fungal invasion. Physiological Plant Pathology, Londres: v.27, p.43-54, 1985.

15. KUNOH, H.; MATSUOKA, K.; KOBAYASHI, I. Ultrastructure of appillae induced in barley coleoptile cells by a pathogen, Erysiphe graminis, and a nonpathogen, E. pisi. Fitopatologia Brasileira. Brasília, v.21, p. 418-425, 1996.

16. LOPES, C. A.; ÁVILA, A. C. Doenças do pimentão. Embrapa Hortaliças: Brasília, 2003, 96p.

17. MASSOLA JUNIOR, N. S.; BEDENDO, I. P. Doenças da mamoneira. In: KIMATI, H; AMORIM, L.; REZENDE, J. A. M. Manual de fitopatologia: doenças das plantas cultivadas. 4ed. São Paulo: Agronômica Ceres, 2005. v.2, p.445-447.

18. NASCIMENTO, A.R.P.; MICHEREFF, S.J.; MARIANO, R.L.R.; GOMES, A.M.A. Elaboração e validação de escala diagramática para cancro bacteriano da videira. Summa Phytopathologica: Botucatu, v.31, n.1, p. 59-63, jan./mar, 2005.

19. NUTTER JUNIOR, F. W.; GLEASON, M.L.; JENCO, J.H.; CHRISTIANS, N.C. Assessing the accuracy, intra-rater repeatability, and inter-rater reliability of disease assessment systems. Phytophatology, St. Paul, v. 83, n. 8, p. 806-812, 1993.

20. RUIZ, R. A. R.; ALFENAS, A. C.; FERREIRA, F. A.; VALE, F. X. R. do. Influência da temperatura, do tempo de molhamento foliar, fotoperíodo e da intensidade de luz sobre a infecção de Puccinia psidii em eucalipto. Fitopatologia Brasileira, Brasília: v.14, p.55-61, 1989b.

21. RUIZ, R. A. R.; ALFENAS, A. C.; MAFFIA, L. A.; BARBOSA, M. M. Progresso da ferrugem do eucalipto, causada por Puccinia psidii, em condições de campo. Fitopatologia Brasileira, Brasília: v.14, p.73-81, 1989a.

22. STADNIK, M. J.; RIVERA, M. C. Oídios. Jaguariúna: Embrapa Meio Ambiente, 2001. 484 p.

23. STRADIOTTO, M. F.; ZAMBOLIM, L. Oídio da seringueira Summa Phytopathologica, Botucatu: v.9, n.1, p.36, 1993. Resumo.

24. TAKAHASHI, K.; AIST, J. R.; ISRAEL, H. W. Distribution of hydrolitic enzymes at barley powdery mildew encounter sites: implications of resistance associated with papilla formation in a compatible system. Physiological Plant Pathology. Londres: v.27, p.167-184, 1985.

25. TENG, P.S., JOHNSON, K.B. Analysis of epidemiological components in yield loss assesment. In: KRANZ, J.; ROTEM, J. (Ed.) Experimental techniques in plant disease epidemiology, New York: Springer-Verlag, 1988, p.179-89.

26. VALE, F. X. R.; ZAMBOLIM, L. Influência da temperatura e da umidade nas epidemias de doenças de plantas. Revisão Anual de Patologia de Plantas, Passo Fundo: v.4, p.149-207, 1996. 